\title{
Impact of serum 25-hydroxyvitamin D on cardiac prognosis in Chinese patients with heart failure
}

\author{
Ya-Min Hou ${ }^{1}$, Jian-Ye Zhao ${ }^{1}$ and Hong-Yan Liu' ${ }^{2, *}$ \\ ${ }^{1}$ Department of Cardiology, Linyin People's Hospital, Linyi, People's Republic of China \\ ${ }^{2}$ Department of General Medicine, Linyin People's Hospital, Linyi, People's Republic of China \\ (Submitted 18 December 2018 - Final revision received 25 February 2019 - Accepted 21 March 2019; First published online 24 July 2019)
}

\begin{abstract}
There is growing evidence that suggests the association of vitamin D status with the development and progression of heart failure (HF). The objective of the present study is to assess the impact of concentration of serum 25-hydroxyvitamin D (25(OH)D) on cardiac prognosis in patients with HF. Between 1 January 2015 and 31 December 2016, we consecutively recruited patients with HF. Patients were followed prospectively for a median duration of 1 year. Serum concentration of $25(\mathrm{OH}) \mathrm{D}$ was measured with competitive chemiluminescent immunoassay. The endpoints were cardiac events, including CVD death and rehospitalisation for worsening HF. Univariate and multivariable adjustments were performed with Cox proportional-hazard regression analyses. The $25(\mathrm{OH}) \mathrm{D}$ concentration was obtained in 343 patients with a median value of $17 \cdot 4$ (interquartile range 12.6-23.4) ng/ml. There were 102 cardiac events, including forty-three deaths and fifty-nine rehospitalisations. Multivariate Cox hazard analysis found that the serum concentration $25(\mathrm{OH}) \mathrm{D}$ was independently associated with cardiac events (hazard ratio $0 \cdot 93,95 \% \mathrm{CI} 0 \cdot 88$, 0.97) and CVD mortality (hazard ratio $0.83 ; 95 \%$ CI 0.77, 0.89) after adjustment for confounding factors. We divided the HF patients into four groups according to the $25(\mathrm{OH}) \mathrm{D}$ quartiles. Kaplan-Meier analysis found that the patients with lower serum $25(\mathrm{OH}) \mathrm{D}$ concentration had a higher risk of cardiac events or CVD mortality than those with high serum $25(\mathrm{OH}) \mathrm{D}$ concentration (log-rank test $P<0 \cdot 001$ and $P=0.032)$. Decreased serum concentrations of $25(\mathrm{OH}) \mathrm{D}$ were associated with cardiac prognosis and CVD mortality in a Chinese population with HF independent of other baseline HF markers.
\end{abstract}

Key words: 25-Hydroxyvitamin D: Vitamin D: Heart failure: Cardiac events: Prognosis: Chinese

Heart failure (HF) is the advanced manifestation of various CVD and portends poor prognosis, especially in patients who are hospitalised with worsening symptoms ${ }^{(1)}$. In a survey reported in 2003, the prevalence of HF was $0 \cdot 4,0 \cdot 9,1.3$ and $1.3 \%$ among populations aged $35-44,45-54,55-64$ and $65-74$ years, respectively, reaching the estimation of more than 4 million HF patients aged $35-74$ years in China ${ }^{(2)}$. HF is perhaps the most serious of all CVD and is a common cause of hospitalisation in China ${ }^{(3,4)}$. It has a poor prognosis despite advances in treatment ${ }^{(5)}$.

Vitamin D plays a role in skeletal health by regulating Ca and $\mathrm{P}$ metabolism. The active metabolite of vitamin D, 1 $\alpha$, 25-dihydroxyvitamin $\mathrm{D}$, binds to the vitamin $\mathrm{D}$ receptor (VDR) that regulates numerous genes involved in fundamental processes of potential relevance to $\mathrm{CVD}^{(6)}$. Vitamin D recently has been proposed to play an important role in cardiovascular health ${ }^{(7)}$. Vitamin D deficiency (VDD) has reached epidemic proportions; this deficiency has been observed to be highly prevalent in the HF community with rates varying from approximately 80 to $95 \%{ }^{(8)}$.
There is growing evidence that suggests that vitamin D status is associated with the development and progression of $\operatorname{HF}^{(9,10)}$. Smaller clinical studies have suggested that low vitamin D status was prevalent in HF patients and is associated with poor outcome ${ }^{(11,12)}$. In patients with HF, low vitamin D levels were associated with adverse outcome and correlate with established clinical correlates and biomarkers ${ }^{(13)}$. A previous study ${ }^{(14)}$ found that VDD was a significant predictor of all-cause mortality and HF rehospitalisation in patients with mild to moderate HF. Another study found that VDD was a significant predictor of reduced survival ${ }^{(15)}$.

25-Hydroxyvitamin D (25(OH)D) is usually considered as a circulating biomarker of vitamin D status. Melamed et al. ${ }^{(16)}$ suggested that the lowest quartile of $25(\mathrm{OH}) \mathrm{D}$ level $(<17.8 \mathrm{ng} / \mathrm{ml})$ was independently associated with all-cause mortality in the general population, while another study found that serum $25(\mathrm{OH}) \mathrm{D}$ was an independent predictor of future adverse CHD events in patients with diabetes mellitus type $2^{(17)}$. Furthermore, Liu et $a l^{(18)}$ demonstrated that adults with inadequate serum 25(OH)D levels

Abbreviations: 25(OH)D, 25-hydroxyvitamin D; BNP, brain natriuretic peptide; CRP, C-reactive protein; eGFR, estimated glomerular filtration rate; HF, heart failure; HR, hazard ratio; IDI, integrated discrimination improvement; IQR, interquartile range; LV, left ventricular; LVEF, LV ejection fraction; NRI, net reclassification improvement; NYHA, New York Heart Association; VDD, vitamin D deficiency; VDR, vitamin D receptor.

* Corresponding author: H.-Y. Liu, email niuuhfdd@126.com 
have significantly higher risk of death from HF and all CVD and allcause premature death.

Interestingly, results evaluating $25(\mathrm{OH}) \mathrm{D}$ in ethnically homogeneous populations might not be broadly generalisable to other racial or ethnic groups ${ }^{(19)}$. Data from Chinese sample studies about the prognostic value of serum 25(OH)D in patients with $\mathrm{HF}$ are rare, hence the purpose of the present study to assess the impact of serum concentrations of serum $25(\mathrm{OH}) \mathrm{D}$ on cardiac prognosis in Chinese patients with HF.

\section{Patients and methods \\ Study population}

Between 1 January 2015 and 31 December 2016, a series of patients with HF from the Heart Failure Clinic at Linyi People's Hospital in China were recruited in this prospective study. The study was performed at geographic latitude $35.05^{\circ} \mathrm{N}$. The diagnosis of $\mathrm{HF}$ was made based on typical signs and symptoms during hospitalisation followed by pulmonary congestion, pleural effusion or left ventricular (LV) enlargement by chest X-ray and/or echocardiography ${ }^{(20)}$. LV ejection fraction (LVEF) and LV end-diastolic diameter of all included patients were assessed through echocardiography. The included criteria were (1) aged over 45 years and (2) inpatients. Patients who used vitamin d/or Ca supplementation during the index year were excluded. There were no other exclusion criteria as long as the patients were willing to provide written informed consent.

For each patient, age, sex, BMI, blood pressure, the seasons into study, New York Heart Association (NYHA)-class, LVEF, LV end-diastolic diameter and medication status from the medical record along with information cause of HF were recorded.

\section{End points and follow-up}

Patients were followed prospectively for a median duration of 1 year. The endpoints were cardiac events, including CVD death and rehospitalisation for worsening HF. CVD death was identified by the Academic Research Consortium criteria ${ }^{(21)}$, including death due to CVD such as CHD, congestive HF, sudden cardiac death or fatal stroke. Sudden cardiac death was defined as death without definite premonitory symptoms or signs and confirmed by the attending physician ${ }^{(22)}$. A rehospitalisation was defined as an unplanned overnight stay in a hospital because of progression of $\mathrm{HF}$ or as a direct result of $\mathrm{HF}^{(9)}$. Cardiovascular events assessment was performed by two trained cardiologists. Blinded to the blood biomarker data, they reviewed the medical records and conducted telephone interviews with the patient or, if not possible, with the relative.

\section{Measurement of serum concentrations of 25- hydroxyvitamin D and brain natriuretic peptide}

The blood samples were prospectively drawn from the antecubital vein the first morning after admission. After centrifugation, the serum samples were immediately stored at $-80^{\circ} \mathrm{C}$ before assay. Serum concentration of $25(\mathrm{OH}) \mathrm{D}$ was measured with competitive chemiluminescent immunoassay in a calibrated Elecsys 2010 (Roche Diagnostics GmbH), with intra- and inter- assay CV of $2 \cdot 0-3.5 \%$ and $2 \cdot 5-4 \cdot 0 \%$, respectively. The detection limit was $3 \mathrm{ng} / \mathrm{ml}$. The 25(OH)D concentrations are therefore used to classify vitamin D status into VDD $(<20 \mathrm{ng} / \mathrm{ml})$ and nor$\mathrm{mal}(\geq 20 \mathrm{ng} / \mathrm{ml})^{(23)}$. Serum brain natriuretic peptide (BNP) concentrations were measured using a commercially available ELISA method (Shiono RIA BNP assay kit, Shionogi \& Co., Ltd). IL-6 was also tested by ELISA method. Other biochemical measurements were done using standard laboratory methods. Estimated glomerular filtration rate (eGFR) was calculated by an equation for the Chinese: eGFR $\left(\mathrm{ml} / \mathrm{min}\right.$ per $\left.1.73 \mathrm{~m}^{2}\right)=175 \times$ creatinine $^{-1.234} \times$ age $^{-0 \cdot 179} \times \operatorname{sex}($ male $=1$, female $=0 \cdot 19)$.

\section{Sample size determination}

A priori power analysis using data from previous research involving $25(\mathrm{OH}) \mathrm{D}^{(24)}$ was conducted to determine the required number of participants $(n)$. Subsequently, the study sample size was calculated using the equations from Whitley \& Ball ${ }^{(25)}$. These calculations found that each group required eleven participants to meet the required power of $99 \%$ at the $\alpha$ value $\leq 0 \cdot 05$. Therefore, the power of the study with more than forty-three participants for each group was calculated to be $>99 \%$ for a type 1 error of 0.05 .

\section{Data handling and statistical analysis}

All data are expressed as medians and interquartile ranges (IQR) or numbers and percentages. $P<0.05$ was considered statistically significant (two sided). Statistical analysis was performed with SPSS for Windows, version 22.0 (SPSS Inc.) and the ROCR package (version 1.0-2).

The $\chi^{2}$ and Mann-Whitney $U$ test were applied for comparing the proportions and medians values between groups. Correlations between 25(OH)D and other parameters were studied by Spearman correlation analysis. Univariate and multivariate analyses with Cox proportional hazard regression was used for assessing the relationship between serum concentration of $25(\mathrm{OH}) \mathrm{D}$ and cardiac events and CVD mortality. The results were revealed as hazard ratios (HR) with $95 \%$ CI. For a more detailed exploration of the $25(\mathrm{OH}) \mathrm{D}$ and outcome, multivariate analysis models to estimate adjusted HR and $95 \%$ CI of cardiac events or CVD mortality for $25(\mathrm{OH}) \mathrm{D}$ quartiles (the 4th quartile as reference) were applied. Furthermore, the relationship between VDD and cardiac events or CVD mortality had also been presented.

Moreover, the net reclassification improvement (NRI) and the integrated discrimination improvement (IDI) were used to measure the quantity of improvement for the correct classification according to the addition of serum $25(\mathrm{OH}) \mathrm{D}$ concentrations to the prediction model. Last, cumulative cardiac events and survival rates were computed using the Kaplan-Meier method and were compared using the log-rank test. We divided the patients into four groups according to the $25(\mathrm{OH}) \mathrm{D}$ quartiles.

\section{Ethics}

The design of the present study was reviewed and approved by the investigational review board of the Linyi People's Hospital. Informed consents were obtained from patients prior to their inclusion in the present study according to the guidance of Declaration of Helsinki. 


\section{Results}

\section{Baseline clinical characteristics}

In the present study, 343 patients were included and finished the follow-up. The $25(\mathrm{OH}) \mathrm{D}$ concentration was obtained from the patients with a median value of $17 \cdot 4$ (IQR 12.6-23.4) ng/ml. A total of 221 patients were defined as VDD; thus, the prevalence was 64.4 (95\% CI 59.4, 69.5) \%. The data suggested significant seasonal differences in $25(\mathrm{OH}) \mathrm{D}$ concentrations, and $25(\mathrm{OH})$ D concentrations were lower in the winter than in other seasons (15.4 (IQR 10.4-19.9) v. 18.6 (IQR 13.2-24.7); $P=0.021$ ). The median value of LVEF was 46 (IQR 34-55) \%, while the LV end-diastolic diameter was 58 (IQR 47-69) $\mathrm{mm}$. In addition, the overall use of $\beta$ blockers, diuretics, angiotensin converting enzyme inhibitors or angiotensin receptor blockers, statins and $\mathrm{Ca}$ channel blockers at admission was 67.9, 89.6, 74.3, 35.6 and $21.0 \%$, respectively. Baseline clinical characteristics are presented in Table 1.

\section{Serum 25-hydroxyvitamin D concentrations and heart failure severity, other biomarkers}

The patients who were in NYHA functional class IV found significantly lower serum concentrations of $25(\mathrm{OH}) \mathrm{D}$ compared with those in classes II and III $(P=0.001 v$. class III and $P<0.001 v$. class II, Fig. 1). As a continuous variable, a correlation between NYHA score and serum concentrations of $25(\mathrm{OH})$ was found ( $r$ (Spearman) $-0 \cdot 303 ; P<0 \cdot 001)$. Negative associations between 25(OH)D and age $(r-0 \cdot 211, P=0.015)$, IL-6 $(r-0.334, P<0.001)$, LV end-diastolic diameter $(r-0.269, P=0.009)$, CRP $(r-0.311$, $P<0.001)$, glucose $(r-0.233, P=0.012)$ and BNP $(r-0.338$, $P<0.001)$ were also obtained. Furthermore, positive associations between $25(\mathrm{OH}) \mathrm{D}$ and LVEF $(r 0.355, P<0.001)$ and eGFR ( $r 0 \cdot 198, P=0.032)$ were recorded.

\section{Comparison between heart failure patients with and} without cardiac events

There were 102 cardiac events, including forty-three deaths and fifty-nine rehospitalisations in patients with HF during the 1-year follow-up period. As shown in Table 2, patients who experienced cardiac events were older, in a more severe NYHA functional class and had a lower BMI, lower eGFR, lower LVEF, higher LV end-diastolic diameter and higher serum concentrations of glucose, CRP, IL- 6 and BNP compared with those who did not. In addition, cardiac events were experienced more likely during winter. Moreover, Fig. 2(a) reveals that patients with cardiac events had lower serum concentrations of 25(OH)D compared with those without (13.2 (IQR 9.0-16.4) v. 19.1 (IQR 14.9-25.8) $\mathrm{ng} / \mathrm{ml}$ ).

\section{Association between serum concentrations of 25- hydroxyvitamin $D$ and cardiac events}

As a continuous variable, $25(\mathrm{OH}) \mathrm{D}$ was associated with decreased risk of cardiac events (OR 0.88, $95 \%$ CI 0.85, 0.92; $P<0 \cdot 001)$ in the univariate model. In multivariable Cox regression analysis, $25(\mathrm{OH}) \mathrm{D}$ was still associated with decreased risk of cardiac events (HR 0.93, $95 \%$ CI 0.88, 0.97; $P=0.003$ ) after adjusting for other significant factors, confirmed in Table 2, including age, BMI, NYHA functional class, seasonal variation, LV end-diastolic diameter, LVEF, eGFR, serum concentration of glucose, C-reactive protein (CRP), BNP and IL-6. The cardiac events increased significantly across decreasing $25(\mathrm{OH}) \mathrm{D}$ quartiles from 9.3 to $55.8 \%(P<0.001$; Table 3$)$. In addition, multivariate analysis models were used to assess cardiac events according to $25(\mathrm{OH}) \mathrm{D}$ quartiles (the highest quartile (Q4) as the reference), with the adjusted HR with $95 \%$ CI were reported. As shown in Table 3, the 1st and 2 nd quartiles of 25(OH)D were compared against Q4 and the HR were 6.68 (95\% CI 3.32, 11.16; $P<0.001)$ and 3.36 (95\% CI 1.98, 7.16; $P=0.001)$, respectively. Furthermore, the association between VDD status and cardiac events had been presented. Interestingly, VDD was a predictor of cardiac events, with the unadjusted and adjusted risks increased by $363 \%$ (HR 4.63; $95 \%$ CI 2.53, 8.47; $P<0.001$ ) and $203 \%$ (HR 3.03; $95 \%$ CI 1.59 , 5.19; $P=0 \cdot 003$ ), respectively.

The NRI and the IDI were used to test the quantity of improvement for the correct reclassification according to the addition of $25(\mathrm{OH}) \mathrm{D}$ serum concentrations to the prediction model I (includes age, BMI, NYHA functional class, seasonal variation, LV end-diastolic diameter, LVEF, eGFR, serum concentration of glucose, CRP, BNP and IL-6). Thirty-two patients with cardiac events were classified in higher risk categories using the inclusion of $25(\mathrm{OH}) \mathrm{D}$ in the prediction model I. Fourteen patients with cardiac events were classified in lower risk categories using the model with the $25(\mathrm{OH}) \mathrm{D}$ and model I as compared with the model with the model I as the only predictor variable. As shown in Table 4 , the inclusion of $25(\mathrm{OH}) \mathrm{D}$ in the prediction model I for the prediction of cardiac events enhanced the NRI $(P=0.003)$ and IDI $(P<0 \cdot 001)$ values, confirming the effective reclassification and discrimination.

Furthermore, as shown in Fig. 3, the patients were divided into four groups according to the $25(\mathrm{OH}) \mathrm{D}$ quartiles. KaplanMeier analysis suggested that patients with a lower serum $25(\mathrm{OH}) \mathrm{D}$ concentrations had a higher risk of cardiac events (log-rank test $P<0 \cdot 001$ ).

\section{Subgroup analysis}

Among the 102 cardiac events, forty-three of them died. The serum concentration of $25(\mathrm{OH}) \mathrm{D}$ in the cases of death was only half when compared with those cases of survival (10.7 (IQR 7.214.8) v. 18.2 (IQR $13 \cdot 8-24 \cdot 1) \mathrm{ng} / \mathrm{ml} ; P<0 \cdot 001)$. As a continuous variable, $25(\mathrm{OH}) \mathrm{D}$ was associated with mortality; when $25(\mathrm{OH}) \mathrm{D}$ was increased by each $1 \mathrm{ng} / \mathrm{ml}$, the unadjusted and adjusted risk were decreased by $25 \%$ (HR 0.75; $95 \%$ CI 0.68, 0.82) and $17 \%$ (HR 0.83; $95 \%$ CI 0.77, 0.89), respectively. Similarly, the association between VDD status and mortality also had been proposed. VDD was a predictor of mortality and the unadjusted and adjusted risks were increased by $386 \%$ (HR 4.86; $95 \%$ CI $1 \cdot 86$, $12.70 ; P<0.001)$ and $239 \%$ (HR 3.39; $95 \%$ CI 1.38, 6.05; $P=0 \cdot 001$ ), respectively (Table 3 ).

Again, the NRI and the IDI were used to test the quantity of improvement for the correct reclassification according to the addition of $25(\mathrm{OH}) \mathrm{D}$ serum concentrations to the prediction model I. Nine patients who died were classified in higher risk categories 
Table 1. Baseline clinical characteristics

(Numbers of patients; medians and interquartile ranges (IQR); numbers and percentages)

\begin{tabular}{|c|c|c|c|c|c|c|c|}
\hline & \multicolumn{2}{|c|}{ All } & \multicolumn{2}{|c|}{ VDD* $^{*}$} & \multicolumn{2}{|c|}{ Normal* $^{*}$} & \multirow[b]{2}{*}{$P$} \\
\hline & $n$ & $\%$ & $n$ & $\%$ & $n$ & $\%$ & \\
\hline$n$ & \multicolumn{2}{|c|}{343} & \multicolumn{2}{|c|}{221} & \multicolumn{2}{|c|}{122} & \\
\hline Age (years) & & & & & & & 0.009 \\
\hline Median & \multirow{2}{*}{\multicolumn{2}{|c|}{$\begin{array}{c}65 \\
56-74\end{array}$}} & \multirow{2}{*}{\multicolumn{2}{|c|}{$\begin{array}{c}68 \\
60-77\end{array}$}} & \multirow{2}{*}{\multicolumn{2}{|c|}{$\begin{array}{c}61 \\
52-68\end{array}$}} & \\
\hline IQR & & & & & & & \\
\hline Male & 190 & $55 \cdot 4$ & 119 & $53 \cdot 8$ & 71 & $58 \cdot 2$ & 0.44 \\
\hline $\mathrm{BMI}\left(\mathrm{kg} / \mathrm{m}^{2}\right)$ & & & & & & & 0.18 \\
\hline Median & \multirow{2}{*}{\multicolumn{2}{|c|}{$\begin{array}{c}24 \cdot 3 \\
22 \cdot 1-26 \cdot 4\end{array}$}} & \multirow{2}{*}{\multicolumn{2}{|c|}{$\begin{array}{c}24 \cdot 8 \\
22 \cdot 5-26 \cdot 8\end{array}$}} & \multirow{2}{*}{\multicolumn{2}{|c|}{$\begin{array}{c}24 \cdot 1 \\
21 \cdot 8-26 \cdot 0\end{array}$}} & \\
\hline IQR & & & & & & & \\
\hline Systolic pressure (mmHg) & & & & & & & 0.32 \\
\hline Median & \multicolumn{2}{|c|}{$\begin{array}{c}118 \\
105-135\end{array}$} & \multirow{2}{*}{\multicolumn{2}{|c|}{$\begin{array}{c}121 \\
109-139\end{array}$}} & & & \\
\hline IQR & & & & & & & \\
\hline Diastolic pressure $(\mathrm{mmHg})$ & & & & & & & 0.65 \\
\hline Median & & & & & & & \\
\hline IQR & & & & & & & \\
\hline Smoking & 87 & 25.4 & 54 & 24.4 & 33 & $27 \cdot 1$ & 0.59 \\
\hline NYHA functional class, II/III/IV (n) & & & & & & & $<0.001$ \\
\hline Included seasonal - Winter & 99 & 28.9 & 76 & 34.4 & 23 & $18 \cdot 9$ & 0.002 \\
\hline Aetiology & & & & & & & \\
\hline Dilated cardiomyopathy & 75 & 21.9 & 45 & $20 \cdot 4$ & 30 & $24 \cdot 6$ & 0.36 \\
\hline Valvular heart disease & 95 & $27 \cdot 7$ & 67 & $30 \cdot 3$ & 28 & 23.0 & 0.14 \\
\hline Hypertrophic cardiomyopathy & 35 & $10 \cdot 2$ & 26 & 11.8 & 9 & $7 \cdot 4$ & 0.20 \\
\hline Hypertensive heart disease & 27 & $7 \cdot 9$ & 23 & $10 \cdot 4$ & 4 & $3 \cdot 3$ & 0.019 \\
\hline $\mathrm{IHD}$ & 70 & $20 \cdot 4$ & 63 & 28.5 & 7 & $5 \cdot 7$ & $<0.001$ \\
\hline Others & 41 & $12 \cdot 0$ & 26 & $11 \cdot 8$ & 15 & $12 \cdot 3$ & 0.89 \\
\hline LV end-diastolic diameter (mm) & & & & & & & $<0.001$ \\
\hline Median & & & & & & & \\
\hline IQR & & & & & & & \\
\hline LV ejection fraction (\%) & & & & & & & $<0.001$ \\
\hline Median & & & & & & & \\
\hline IQR & & & & & & & \\
\hline Medications & & & & & & & \\
\hline$\beta$-Blockers & 233 & 67.9 & 147 & 66.5 & 86 & $70 \cdot 5$ & 0.45 \\
\hline Diuretics & 305 & 88.9 & 198 & 89.6 & 107 & $87 \cdot 7$ & 0.59 \\
\hline ACE inhibitors and/or ARB & 255 & $74 \cdot 3$ & 162 & $73 \cdot 3$ & 73 & $76 \cdot 2$ & 0.55 \\
\hline Statins & 122 & $35 \cdot 6$ & 75 & 33.9 & 47 & 38.5 & 0.39 \\
\hline Ca channel blockers & 72 & $21 \cdot 0$ & 43 & 19.5 & 29 & 23.8 & 0.35 \\
\hline Blood biomarkers & & & & & & & \\
\hline Albumin $(\mathrm{g} / \mathrm{l})$ & & & & & & & 0.65 \\
\hline Median & & & & & & & \\
\hline IQR & & & & & & & \\
\hline Glucose $(\mathrm{mmol} / \mathrm{l})$ & & & & & & & 0.010 \\
\hline Median & & & & & & & \\
\hline IQR & & & & & & & \\
\hline CRP (mg/l) & & & & & & & $<0.001$ \\
\hline Median & & & & & & & \\
\hline IQR & & & & & & & \\
\hline BNP (pg/ml) & & & & & & & $<0.001$ \\
\hline Median & & & & & & & \\
\hline IQR & & & & & & & \\
\hline IL-6 (pg/ml) & & & & & & & $<0.001$ \\
\hline Median & & & & & & & \\
\hline IQR & & & & & & & \\
\hline $25(\mathrm{OH}) \mathrm{D}(\mathrm{ng} / \mathrm{ml})$ & & & & & & & $<0.001$ \\
\hline Median & & & & & & & \\
\hline IQR & & & & & & & \\
\hline eGFR $\left(\mathrm{ml} / \mathrm{min}\right.$ per $\left.1.73 \mathrm{~m}^{2}\right)$ & & & & & & & 0.009 \\
\hline Median & & & & & & & \\
\hline IQR & & & & & & & \\
\hline
\end{tabular}

VDD, vitamin D deficiency; NYHA, New York Heart Association; LV, left ventricular; ACE, angiotensin-converting enzyme; ARB, angiotensin receptor blocker; CRP, C-reactive protein; BNP, brain natriuretic peptide; $25(\mathrm{OH}) \mathrm{D}, 25$-hydroxyvitamin $\mathrm{D}$; eGFR, estimated glomerular filtration rate.

* The $25(\mathrm{OH})$ D concentrations are used to classify vitamin D status into VDD $(<20 \mathrm{ng} / \mathrm{ml})$ and normal $(\geq 20 \mathrm{ng} / \mathrm{ml})$.

and two patients who died were classified in lower risk categories using the model with the model I and $25(\mathrm{OH}) \mathrm{D}$ level as compared with the model with the model I as the only predictor variable. As shown in Table 4 , the inclusion of $25(\mathrm{OH}) \mathrm{D}$ in the prediction model
I for the prediction of mortality enhanced the NRI $(P=0.001)$ and IDI $(P<0.001)$ values, confirming the effective reclassification and discrimination. Furthermore, as shown in Fig. 4, the patients were divided into four groups according to the $25(\mathrm{OH}) \mathrm{D}$ quartiles. 
Fig. 1. Serum 25-hydroxyvitamin $\mathrm{D}(25(\mathrm{OH}) \mathrm{D})$ concentrations and heart failure severity (defined by New York Heart Association (NYHA) functional class).

Table 2. Univariate analyses for cardiac event and mortality (Hazard ratios (HR) and $95 \%$ confidence intervals)

\begin{tabular}{|c|c|c|c|c|c|c|}
\hline & \multicolumn{3}{|c|}{ Cardiac event } & \multicolumn{3}{|c|}{ Mortality } \\
\hline & $\mathrm{HR}$ & $95 \% \mathrm{Cl}$ & $P$ & $\mathrm{HR}$ & $95 \% \mathrm{Cl}$ & $P$ \\
\hline Age & 1.06 & $1.04,1.10$ & $<0.001$ & 1.13 & $1.07,1 \cdot 18$ & $<0.001$ \\
\hline Male & 1.35 & $0.55,3.76$ & 0.93 & 1.28 & $0.65,3.01$ & 0.74 \\
\hline BMI & 1.06 & $1.01,1.12$ & 0.024 & $1 \cdot 10$ & $1.05,1 \cdot 16$ & 0.005 \\
\hline Systolic pressure & 0.99 & $0.99,1.03$ & 0.39 & 1.02 & $0.99,1.04$ & 0.27 \\
\hline Diastolic pressure & 1.04 & $0.97,1.22$ & 0.23 & 1.05 & $0.98,1.17$ & 0.42 \\
\hline Smoking & 0.75 & $0.44,1.18$ & 0.32 & 0.93 & $0.50,1.32$ & 0.27 \\
\hline NYHA functional class & 1.51 & $1.14,2.02$ & 0.002 & 1.74 & $1 \cdot 21,2 \cdot 11$ & 0.001 \\
\hline Included seasonal - Winter & 2.07 & $1.03,3.82$ & 0.031 & $2 \cdot 15$ & $1 \cdot 16,3.76$ & 0.029 \\
\hline Aetiology & $1 \cdot 12$ & $0.74,1.87$ & 0.19 & 1.36 & $0.93,1.93$ & 0.15 \\
\hline LV end-diastolic diameter & 1.03 & $1.01,1.09$ & 0.011 & 1.09 & $1.03,1.16$ & $<0.001$ \\
\hline LV ejection fraction & 0.89 & $0.82,0.95$ & 0.003 & 0.83 & $0.75,0.90$ & $<0.001$ \\
\hline \multicolumn{7}{|l|}{ Medications } \\
\hline$\beta$-Blockers & 1.33 & $0.82,2 \cdot 14$ & 0.15 & 1.44 & $0.95,2.09$ & 0.09 \\
\hline ACE inhibitors and/or ARB & 0.78 & $0.48,1.44$ & 0.32 & 0.93 & $0.85,1.10$ & 0.12 \\
\hline Statins & 1.05 & $0.68,1.66$ & 0.83 & $1 \cdot 15$ & $0.76,1.54$ & 0.65 \\
\hline Ca channel blockers & $1 \cdot 20$ & $0.75,1.95$ & 0.45 & 1.87 & $1.11,3.02$ & $0 \cdot 10$ \\
\hline \multicolumn{7}{|l|}{ Blood biomarkers } \\
\hline Albumin & $1 \cdot 16$ & $0.96,1.44$ & 0.092 & 1.24 & $1.03,1.45$ & 0.062 \\
\hline Glucose & 1.07 & $1.01,1.15$ & 0.027 & $1 \cdot 13$ & $1.03,1.23$ & 0.013 \\
\hline CRP & $1 \cdot 10$ & $1.02,1.22$ & 0.042 & $1 \cdot 15$ & $1.05,1.24$ & 0.021 \\
\hline BNP & 1.01 & $1.00,1.02$ & 0.009 & 1.03 & $1.01,1.06$ & $<0.001$ \\
\hline IL-6 & $1 \cdot 18$ & $1.03,1.42$ & 0.006 & $1 \cdot 15$ & $1.05,1.26$ & 0.001 \\
\hline $25(\mathrm{OH}) \mathrm{D}$ & 0.88 & $0.85,0.92$ & $<0.001$ & 0.75 & $0.68,0.82$ & $<0.001$ \\
\hline eGFR $\left(\mathrm{ml} / \mathrm{min}\right.$ per $\left.1.73 \mathrm{~m}^{2}\right)$ & 0.98 & $0.97,0.99$ & 0.036 & 0.96 & $0.94,0.98$ & 0.021 \\
\hline
\end{tabular}

NYHA, New York Heart Association; LV, left ventricular; ACE, angiotensin-converting enzyme; ARB, angiotensin receptor blocker; CRP, C-reactive protein; BNP, brain natriuretic peptide; 25(OH)D, 25-hydroxyvitamin D; eGFR, estimated glomerular filtration rate.

Kaplan-Meier analysis suggested that the patients with a lower serum 25(OH)D concentrations had a higher risk of mortality (log-rank test $P=0 \cdot 032$ ).

During the follow through, eight patients experienced noncardiovascular deaths (six patients died from cancer and two from other causes). Adjusted analyses were repeated for all-cause mortality and similar results were obtained with a HR for VDD of 4.24 (95\% CI 1.69, 8.03; $P<0.001$ ). Similarly, the inclusion of $25(\mathrm{OH}) \mathrm{D}$ in the prediction model I for the prediction of all-cause mortality enhanced the NRI $(P=0.009)$ and IDI $(P=0.002)$ values, confirming the effective reclassification and discrimination. 
(a)

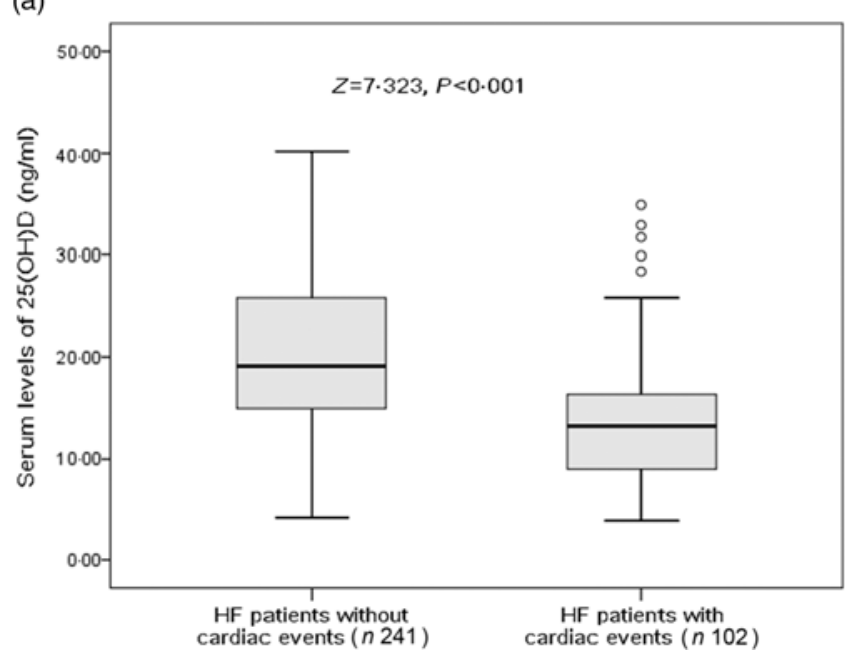

(b)

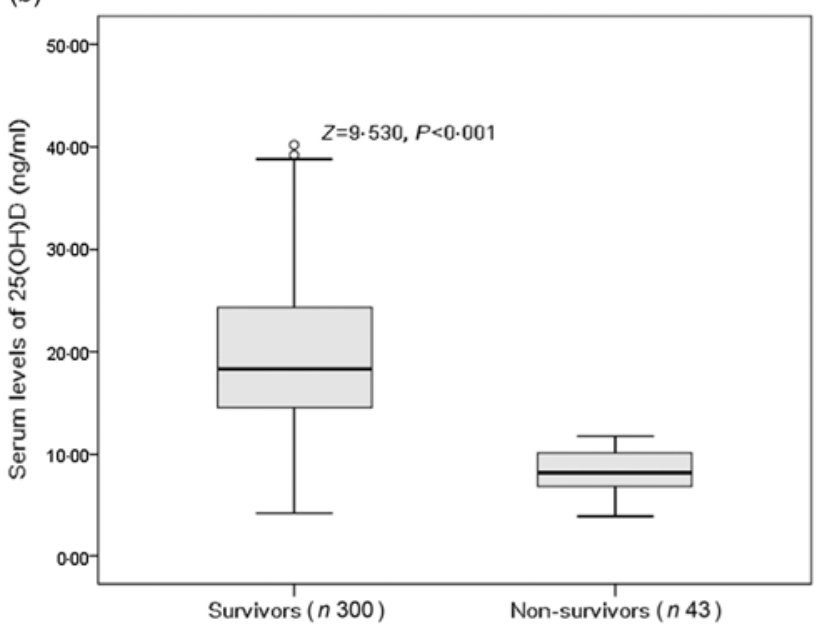

Fig. 2. Comparisons of serum 25 -hydroxyvitamin $D(25(\mathrm{OH}) \mathrm{D})$ concentrations between different groups. (a) Comparisons of serum $25(\mathrm{OH}) \mathrm{D}$ concentrations between heart failure (HF) patients with and without cardiac events; (b) comparisons of serum 25(OH)D concentrations between survivors and non-survivors of HF. Data were analysed by the Mann-Whitney $U$ test. All data are medians and interquartile ranges.

Table 3. Univariate and multivariate analyses for cardiac events (CE) and mortality according to 25-hydroxyvitamin D (25(OH)D) quartiles* (Numbers and percentages; hazard ratios (HR) and $95 \%$ confidence intervals)

\begin{tabular}{|c|c|c|c|c|c|c|c|c|}
\hline \multirow[b]{2}{*}{ 25(OH)D† } & \multirow[b]{2}{*}{$\mathrm{CE} / N$} & \multirow[b]{2}{*}{$\%$} & \multicolumn{3}{|c|}{ Univariate analysis } & \multicolumn{3}{|c|}{ Multivariable-adjusted $\neq$} \\
\hline & & & Crude HR & $95 \% \mathrm{Cl}$ & $P \S$ & HR & $95 \% \mathrm{Cl}$ & $P \S$ \\
\hline \multicolumn{9}{|l|}{ Cardiac events } \\
\hline Quartile 1 & $48 / 86$ & $55 \cdot 8$ & $12 \cdot 32$ & $5 \cdot 32,28 \cdot 61$ & $<0.001$ & $6 \cdot 68$ & $3 \cdot 32,11 \cdot 16$ & $<0.001$ \\
\hline Quartile 2 & $30 / 85$ & $35 \cdot 3$ & $5 \cdot 32$ & $2 \cdot 27,12 \cdot 48$ & $<0.001$ & 3.36 & $1 \cdot 98,7 \cdot 16$ & 0.001 \\
\hline Quartile 3 & $16 / 86$ & $18 \cdot 6$ & $2 \cdot 23$ & $0.90,5.53$ & 0.078 & 1.59 & $0.66,3.77$ & 0.36 \\
\hline Quartile 4 & $8 / 86$ & $9 \cdot 3$ & Reference & & & Reference & & \\
\hline VDD $v$. normal & \multicolumn{2}{|c|}{$87 / 221$ v. $15 / 107$} & 4.63 & $2.53,8.47$ & $<0.001$ & 3.03 & $1.59,5.19$ & 0.003 \\
\hline Mortality & Death/N & $\%$ & & & & & & \\
\hline Quartile 1 & $25 / 86$ & 29.1 & $17 \cdot 21$ & $3.93,75.43$ & $<0.001$ & 7.54 & $2 \cdot 47,15 \cdot 15$ & $<0.001$ \\
\hline Quartile 2 & $11 / 85$ & $12 \cdot 9$ & $6 \cdot 24$ & $1.34,29.08$ & 0.009 & 3.55 & $1.62,9.04$ & 0.006 \\
\hline Quartile 3 & $5 / 86$ & $5 \cdot 8$ & 2.59 & $0.49,13 \cdot 75$ & 0.25 & 1.72 & $0.55,5.04$ & 0.62 \\
\hline Quartile 4 & $2 / 86$ & $2 \cdot 3$ & Reference & & & Reference & & \\
\hline VDD v. normal & \multicolumn{2}{|c|}{$38 / 221$ v. $5 / 107$} & 4.86 & $1 \cdot 86,12 \cdot 70$ & $<0.001$ & 3.39 & $1.38,6.05$ & 0.001 \\
\hline
\end{tabular}

VDD, vitamin D deficiency; HF, heart failure; NYHA, New York Heart Association; LV, left ventricular; LVEF, LV ejection fraction; eGFR, estimated glomerular filtration rate; CRP, C-reactive protein; BNP, brain natriuretic peptide.

${ }^{*}$ Cardiac events included CVD deaths and rehospitalisations for worsening HF.

† 25(OH)D in quartile $1(<12.6 \mathrm{ng} / \mathrm{ml})$, quartile $2(12.6-17.4 \mathrm{ng} / \mathrm{ml})$, quartile $3(17.5-23.4 \mathrm{ng} / \mathrm{ml})$ and quartile 4 (>23.4 ng/ml). VDD was defined as $25(\mathrm{OH}) \mathrm{D}<20.0 \mathrm{ng} / \mathrm{ml}$.

$\ddagger$ Adjusted for significant factors confirmed in Table 2, including age, BMI, NYHA functional class, included seasonal, LV end-diastolic diameter, LVEF, eGFR, serum concentration of glucose, CRP, BNP and IL-6.

$\S P$ value for trend $<0.001$

\section{Discussion}

The steroid hormone vitamin $\mathrm{D}$ regulates gene expression of many genes that play a prominent role in the progression of HF such as cytokines and hormones ${ }^{(13)}$. In the present study, we reported the prevalence of VDD in a Chinese cohort of HF patients and described the cardiac prognostic value in this population. The present study found that serum concentration of $25(\mathrm{OH}) \mathrm{D}$ was a novel prognostic marker for the risk stratification of patients with HF. More importantly, VDD was a significant predictor of increased cardiac events and reduced survival in patients with HF.

Consistent with our finding, Schierbeck et al. ${ }^{(26)}$ highlighted that vitamin D was independently associated with all-cause and CVD mortality in patients with HF in a relatively small prospective study ( $n$ 148), while another study confirmed that a low $25(\mathrm{OH}) \mathrm{D}$ concentration was associated with a poor prognosis in HF patients ${ }^{(9)}$. Similar findings were found in a study of 220 ischaemic stroke patients where higher. The 90-d mortality rates were significantly associated with lower levels of $25(\mathrm{OH}) \mathrm{D}^{(27)}$. Another study demonstrated that VDD was associated with increased arterial wall stiffness in a young population, suggesting the increased risk for all-cause mortality in vitamin $\mathrm{D}$ deficient subjects $^{(28)}$. Kestenbaum et al. ${ }^{(29)}$ found that serum $25(\mathrm{OH}) \mathrm{D}$ concentrations $<15 \mathrm{ng} / \mathrm{ml}$ were associated with a $29 \%$ greater risk for mortality among older adults. In a meta-analysis of 77155 participants of mixed ethnicity, the risk of any early death 
Table 4. Statistics for model fit and improvement with addition of vitamin D deficiency (VDD) predicted on the prediction of cardiac events and mortality*

\begin{tabular}{lllrr}
\hline & & \multicolumn{2}{c}{ Prediction model II (model I + } \\
\cline { 3 - 4 } & & \multicolumn{2}{c}{ VDD) } & \\
\cline { 3 - 4 } & Prediction model It & Model II & $95 \% \mathrm{Cl}$ & $P$ \\
\hline Cardiac events & & & & \\
NRI & - & 0.403 & $0.176,0.687$ & $<003$ \\
IDI & - & 0.155 & $0.089,0.279$ & $<0.001$ \\
Mortality & - & & & 0.001 \\
NRI & - & 0.448 & $0.204,0.794$ & $<0.001$ \\
IDI & - & 0.183 & $0.114,0.302$ & \\
\hline
\end{tabular}

NRI, net reclassification improvement; IDI, integrated discrimination improvement; 25(OH)D, 25-hydroxyvitamin D; NYHA, New York Heart Association; LV, left ventricular; LVEF, LV ejection fraction; eGFR, estimated glomerular filtration rate; CRP, C-reactive protein; BNP, brain natriuretic peptide.

*VDD was defined as $25(\mathrm{OH}) \mathrm{D}<20.0 \mathrm{ng} / \mathrm{ml}$.

† Prediction model I included age, BMI, NYHA functional class, included seasonal, LV end-diastolic diameter, LVEF, eGFR, serum concentration of glucose, CRP, BNP and IL-6.

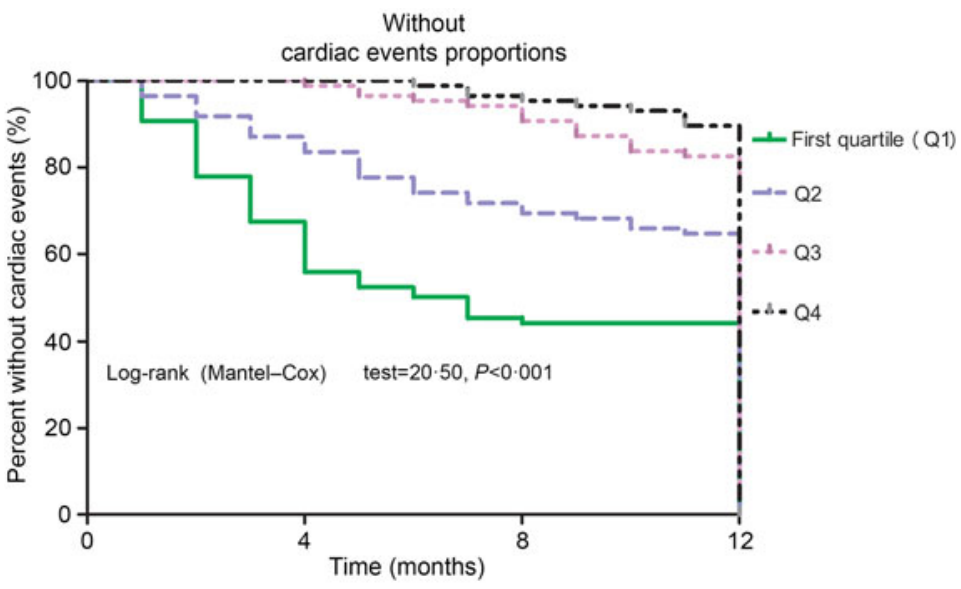

Fig. 3. Kaplan-Meier analysis of cardiac events according to the 25 -hydroxyvitamin $\mathrm{D}(25(\mathrm{OH}) \mathrm{D})$ quartiles. The patients with lower serum $25(\mathrm{OH}) \mathrm{D}$ concentrations had a higher risk of cardiac events (log-rank test $P<0.001$ ).

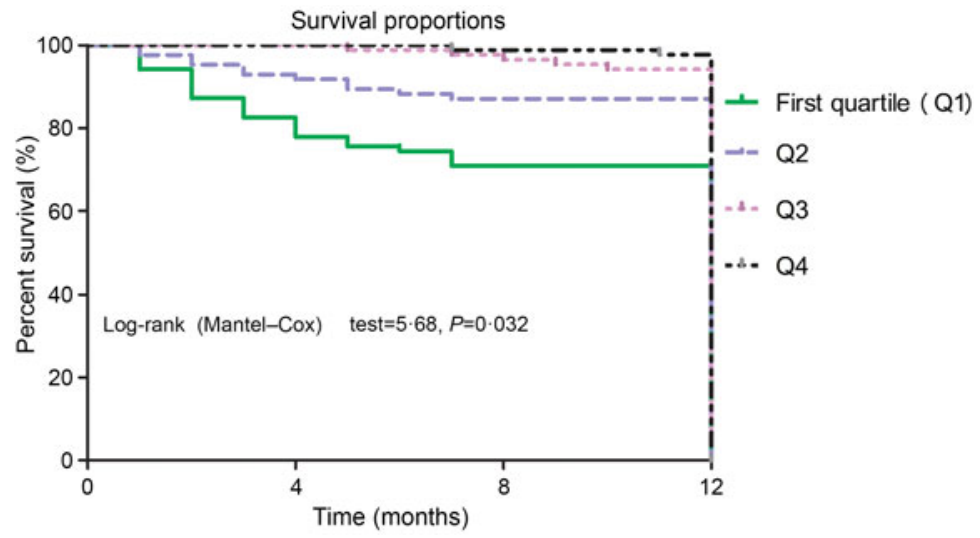

Fig. 4. Kaplan-Meier analysis of CVD mortality according to the 25-hydroxyvitamin $\mathrm{D}(25(\mathrm{OH}) \mathrm{D})$ quartiles. The patients with lower serum $25(\mathrm{OH}) \mathrm{D}$ concentrations had a higher risk of CVD mortality (log-rank test $P=0.032$ ). 
was increased by $35(95 \% \mathrm{CI} 31,42) \%$ for the lowest $v$. the highest quartile of $25(\mathrm{OH}) \mathrm{D}$ level ${ }^{(30)}$. A population-based study of 9146 younger adults found significant associations with all-cause mortality but not CVD mortality ${ }^{(31)}$. In contrast, no association between vitamin $\mathrm{D}$ and mortality was found in a prospective study of older men ${ }^{(32)}$. Similarly, Gerling et $a l .{ }^{(33)}$ found that serum total $25-\mathrm{OH}$ vitamin D was inversely associated with mortality risk, and this association was attenuated by several competing risk factors. They suggested that overall $25-\mathrm{OH}$ vitamin D added little prognostic value over established risk factors. In the present study, we calculated the NRI and found that, even though 25(OH)D was associated with mortality, it added very little additional prognostic value.

The prevalence of VDD (25(OH)D levels $<20 \mathrm{ng} / \mathrm{ml})$ was present in $75.2 \%$ of the 10100 people aged $40-75$ years in Lanzhou, China ${ }^{(34)}$. Overall, in the present study, $64.4 \%$ of the $\mathrm{HF}$ was defined as VDD $(25(\mathrm{OH}) \mathrm{D}$ levels $<20 \mathrm{ng} / \mathrm{ml})$ and $86.6 \%$ had $25(\mathrm{OH}) \mathrm{D}$ levels $<30 \mathrm{ng} / \mathrm{ml}$. Similarly, another study found that $75 \%$ of patients had VDD by most guidelines $(<20 \mathrm{ng} / \mathrm{ml})^{(9)}$. Among subjects with chronic HF, $97 \cdot 8 \%$ presented VDD $(25(\mathrm{OH}) \mathrm{D}<30 \mathrm{ng} / \mathrm{ml})$ and severe $(<10 \mathrm{ng} / \mathrm{ml})$ in $66.7 \%{ }^{(35)}$. However, another study reported that VDD $(\leq 20 \mathrm{ng} / \mathrm{ml})$ was prevalent in $43 \%$ of the 148 HF outpatients ${ }^{(26)}$. There were variations in sites of study, sampling and testing methods, including criteria, racial or ethnic, culture, dietary and economic status between the various studies. Those variations make it difficult to compare different studies. In general, VDD is a common presence in patients with HF.

The association between low vitamin $\mathrm{D}$ and an activated RAS and inflammatory status had been suggested ${ }^{(9)}$. In the present study, we also found an inverse correlation between $25(\mathrm{OH}) \mathrm{D}$ and inflammatory status (CRP and IL-6). Two previous studies had found that high levels of CRP were a common finding in patients with HF and were associated with a poor prognosis ${ }^{(36,37)}$, which was supported by our finding. In addition, a study revealed a sex-specific association between VDD and LV dilation $^{(35)}$, in which our research had similar findings.

The relationship between decreasing low concentrations of $25(\mathrm{OH}) \mathrm{D}$ and cardiac prognosis in patients with HF reported in the present study was no proof of a causal relation due to the observational design; however, there are mechanisms through which low concentrations of $25(\mathrm{OH}) \mathrm{D}$ could have harmful effects on the cardiovascular system. First, vitamin D was converted into an active metabolite calcitriol (1,25-hydroxyvitamin $\mathrm{D}_{3}$ ) in the kidney. Calcitriol is a negative regulator of the renin-angiotensin system and cardiomyocyte proliferation, and suppresses immune and inflammatory responses ${ }^{(15)}$. Calcitriol is also directly involved in Ca-dependent cellular processes, including the synthesis of Ca-binding protein, the activation of adenylate cyclase, the rapid activation of voltage-dependent $\mathrm{Ca}$ channels and the influx, reuptake and release of $\mathrm{Ca}$ from the sarcoplasmic reticulum ${ }^{(38)}$. This altered intracellular handling of ionised Ca could also contribute to the impaired contractility of the myocardium in HF patients ${ }^{(39)}$. VDR knockout mice develop typical signs of $\mathrm{HF}$, including activation of the reninangiotensin-aldosterone system, cardiac hypertrophy, high blood pressure and increased levels of atrial natriuretic peptide ${ }^{(40)}$. Second, 25(OH)D controls inflammatory and immune responses keeping them within physiological boundaries $^{(6)}$. An important feature of the modulation of immune function by $25(\mathrm{OH}) \mathrm{D}$ is suppression of the development and responses of $\mathrm{TH}_{1}$ and $\mathrm{TH}_{17}$ cells and favouring Treg and $\mathrm{TH}_{2}$ cells $^{(41)}$. Proinflammatory cytokine are down-regulated and the anti-inflammatory ones such as IL- 4 and IL-10 are upregulated $^{(10,36-37)}$. Third, a relationship between vitamin D status and endothelial function had been suggested. Vitamin D may attenuate the adverse effects (including increased NFKB expression) of advanced glycation end-products on endothelial cells $^{(42)}$. A previous study demonstrated that 25(OH)D downregulated tissue factor and up-regulated thrombomodulin expression in cultured monocytic cells via a VDR-mediated mechanism ${ }^{(33)}$. Last, parathyroid hormone is elevated in patients with VDD. Parathyroid hormone has been shown to be an independent predictor of all-cause and cardiovascular mortality in patients with $\mathrm{HF}^{(26)}$. In addition, there was experimental evidence that VDD results in maladaptive cardiac remodelling attributable to progressive myocyte hypertrophy and interstitial fibrosis $^{(6)}$.

A more meaningful study was whether vitamin supplementation can improve the prognosis, especially for HF patients with VDD. However, our cross-sectional design could not obtain any causal relation. It remains unclear if vitamin D supplementation is beneficial in preventing HF or if it could be a therapeutic addendum in the treatment of $\mathrm{HF}^{(13)}$. Unfortunately, vitamin D supplementation trials show mixed results. Interestingly, a previous study suggested that vitamin D supplementation has great benefits as an anti-inflammatory agent in infants with chronic HF by helping acceleration of the clinical improvement and cytokine profile balance ${ }^{(43)}$. Previous studies found that vitamin D supplementation was significantly associated with better survival, specifically in patients with documented deficiency ${ }^{(14)}$, and vitamin $\mathrm{D}$ may be an important adjunct to standard HF therapy ${ }^{(44)}$ and improve quality of life $(\mathrm{QOL})^{(45)}$. In contrast, a study found that treatment with Vitamin D supplementation did not show clear evidence of benefit for preventing HF or influencing its clinical course ${ }^{(46)}$, while another study found that vitamin D supplementation has no beneficial effects on improvement of LV function and exercise tolerance in chronic HF patients ${ }^{(47)}$. Witham et al. ${ }^{(48)}$ found that vitamin D supplementation did not improve functional capacity or QOL in a short-term trial of 105 older patients with $\mathrm{HF}$ and vitamin D insufficiency. These results bring into questions whether vitamin $\mathrm{D}$ is a risk factor for $\mathrm{HF}$, a marker of $\mathrm{HF}$ disease severity or has a true pathological role. The influence of vitamin D on all these pathways in models of HF merits further exploration.

A limitation of the present study was the relatively small sample size, which made it impossible to draw firm conclusions with regard to hard endpoints. In addition, we only studied a Chinese HF population. Second was that the present study analysed a single measurement of $25(\mathrm{OH}) \mathrm{D}$, which may not adequately reflect the long-term vitamin D status in these patients. In addition, newer studies suggest that $30 \mathrm{ng} / \mathrm{ml}$ was a better indicator of sufficiency; this has been proposed as the minimum level needed to 
suppress parathormone (PTH) maximally ${ }^{(26)}$. In the present study, $20 \mathrm{ng} / \mathrm{ml}$ was used. Third, as there is a strong link between renal function and heart disease, and since the kidneys transform vitamin D to its active form, it is likely that there will be an interaction between the prognostic importance of vitamin D, PTH and renal function ${ }^{(49)}$. Many studies reported that PTH was the truly important role as a prognostic factor in HF. We were not able to identify this interaction, most likely due to fact that the PTH concentration was not assessed. Fourth, some severe deterioration of LVEF might have been excluded due to the use of vitamin and/or Ca supplementation. In addition, we might include mostly the patients with HF preserved, not reduced, ejection fraction. Judging the HF occurrence only on the basis of clinical symptoms may be sometimes misleading. Last, any causal relationship could not be proved due to the observational study design. We could not determine that VDD was a marker of worse outcomes or a biomarker of inadequately treated. The true mechanism of VDD might be that the patients with raised NYHA class were more prone to be immobilised; thus, the synthesis of active forms of vitamin D was impaired. The addition of the simple survey of declared sun exposure could have positive impact on the methodology of the study. Whether maintaining the serum concentration of vitamin D to normal would be beneficial for prognosis requires further controlled clinical trials to confirm.

\section{Conclusion}

In short, decreased serum concentrations of $25(\mathrm{OH}) \mathrm{D}$ were associated with cardiac prognosis and CVD mortality in a Chinese population with HF independent of other baseline HF markers. Serum 25(OH)D concentration appears to represent a novel prognostic marker for the risk stratification of patients with HF. Since it plays an important role in the multiple stages of $\mathrm{HF}$ progression, $25(\mathrm{OH}) \mathrm{D}$ is suggested as a prognostic biomarker and worthy of further research as a possible therapeutic target.

\section{Acknowledgements}

We are grateful to the staff in the Department of Cardiology, the Linyi People's Hospital, for their support with patient recruitment. We are also grateful to the patients who were included the present study. The authors also acknowledge the contribution of the reviewers who have helped us improve the manuscript.

L. H.-Y. had full access to all the data in the study and takes responsibility for the integrity of the data and the accuracy of the data analysis. Study concept and design: H. Y.-M., Z. J.-Y., L. H.-Y.; acquisition of data: H. Y.-M., L. H.-Y.; analysis and interpretation of data: H. Y.-M., Z. J.-Y.; drafting of the manuscript: H. Y.-M.; critical revision of the manuscript for important intellectual content: Z. J.-Y., L. H.-Y.; administrative, technical or material support: H. Y.-M., Z. J.-Y., L. H.-Y.; study supervision: H. Y.-M.

There were no conflicts of interest.

\section{References}

1. Zhang Y, Zhang J, Butler J, et al. (2017) Contemporary epidemiology, management, and outcomes of patients hospitalized for heart failure in China: results from the China heart failure (China-HF) registry. J Card Fail 23, 868-875.

2. National Center for Cardiovascular Diseases, China (2014) Report on Cardiovascular Diseases in China (2011), pp. 1-4 [HuShengshou and KongLingzhi, editors]. Beijing, China: Encyclopedia of China Publishing House.

3. Jiang H \& Ge J (2009) The epidemiology and clinical management of cardiomyopathies and heart failure in China. Heart $\mathbf{9 5}$, $1727-1731$.

4. Ariely R, Evans K \& Mills T (2013) Heart failure in China: a review of the literature. Drugs $\mathbf{7 3}, 689-701$.

5. Jessup M \& Brozena S (2003) Heart failure. New EnglJ Med 348 , 2007-2018.

6. Norman PE, Powell JT (2014) Vitamin D and cardiovascular disease. Circ Res 114, 379-393.

7. Anderson JL, May HT, Horne BD, et al. (2010) Relation of vitamin D deficiency to cardiovascular risk factors, disease status, and incident events in a general healthcare population. $A m J$ Cardiol 106, 963-968.

8. Agarwal M, Phan A, Willix R, et al. (2011) Is vitamin D deficiency associated with heart failure? A review of current evidence. J Cardiovasc Pharmacol Ther 16, 354-363.

9. Liu CY, Voors AA, van Veldhuisen DJ, et al. (2011) Vitamin D status and outcomes in heart failure patients. Eur J Heart Fail 13, 619-625.

10. Dobnig H, Pilz S, Scharnagl H, et al. (2008) Independent association of low serum 25-hydroxyvitamin D and 1,25-dihydroxyvitamin $\mathrm{D}$ levels with all-cause and cardiovascular mortality. Arch Intern Med 168, 1340-1349.

11. Boxer RS, Kenny AM,Cheruvu VK, et al. (2010) Serum 25hydroxyvitamin D concentration is associated with functional capacity in older adults with heart failure. Am Heart J 160, 893-899.

12. Zittermann A, Schleithoff SS, Gotting C, et al. (2008) Poor outcome in end-stage heart failure patients with low circulating calcitriol levels. Eur J Heart Fail 10, 321-327.

13. Meems LM, Van der Harst P, van Gilst WH, et al. (2011) Vitamin D biology in heart failure: molecular mechanisms and systematic review. Curr Drug Targets 12, 29-41.

14. Vacek JL, Vanga SR, Good M, et al. (2012) Vitamin D deficiency and supplementation and relation to cardiovascular health. $\mathrm{Am}$ J Cardiol 109, 359-363.

15. Gotsman I, Shauer A, Zwas DR, et al. (2012) Vitamin D deficiency is a predictor of reduced survival in patients with heart failure; vitamin D supplementation improves outcome. Eur J Heart Fail 14, 357-366.

16. Melamed ML, Michos ED, Post W, et al. (2008) 25Hydroxyvitamin D levels and the risk of mortality in the general population. Arch Intern Med 168, 1629-1637.

17. Heidari B, Nargesi AA, Hafezi-Nejad N, et al. (2015) Assessment of serum 25-hydroxy vitamin D improves coronary heart disease risk stratification in patients with type 2 diabetes. $\mathrm{Am}$ Heart J 170, 573-579.

18. Liu L, Chen M, Hankins SR, et al. (2012) Serum 25-hydroxyvitamin $\mathrm{D}$ concentration and mortality from heart failure and cardiovascular disease, and premature mortality from all-cause in United States adults. Am J Cardiol 110, 834-839.

19. Robinson-Cohen C, Hoofnagle AN, Ix J H, et al. (2013) Racial differences in the association of serum 25-hydroxyvitamin D concentration with coronary heart disease events. JAMA 310, 179-188. 
20. Funayama A, Shishido T, Netsu S, et al. (2011) Serum pregnancy-associated plasma protein $\mathrm{A}$ in patients with heart failure. J Card Fail 17, 819-826.

21. Tu WJ, Ma GZ, Ni Y, et al. (2017) Copeptin and NT-proBNP for prediction of all-cause and cardiovascular death in ischemic stroke. Neurology 88, 1899-1905.

22. Narumi T, Watanabe T, Kadowaki S, et al. (2014) Impact of serum omentin-1 levels on cardiac prognosis in patients with heart failure. Cardiovasc Diabetol 13, 84 .

23. Holick MF (2007) Vitamin D deficiency. $N$ Engl J Med 357, 266-281.

24. Afarideh M, Ghanbari P, Noshad S, et al. (2016) Raised serum 25-hydroxyvitamin $\mathrm{D}$ levels in patients with active diabetic foot ulcers. Br J Nutr 115, 1938-1946.

25. Whitley E \& Ball J (2002) Statistics review 4: sample size calculations. Crit Care 6, 335-341.

26. Schierbeck LL, Jensen TS, Bang U, et al. (2011) Parathyroid hormone and vitamin D - markers for cardiovascular and allcause mortality in heart failure. Eur J Heart Fail 13, 626-632.

27. Tu WJ, Zhao SJ, Xu DJ, et al. (2014) Serum 25-hydroxyvitamin D predicts the short-term outcomes of Chinese patients with acute ischaemic stroke. Clin Sci 126, 339-346.

28. Dong Y, Stallmann-Jorgensen IS, Pollock NK, et al. (2010) A 16-week randomized clinical trial of 2000 international units' daily vitamin $\mathrm{D}_{3}$ supplementation in black youth: 25-hydroxyvitamin D, adiposity, and arterial stiffness. J Clin Endocrinol Metab 95, 4584-4591.

29. Kestenbaum B, Katz R, De Boer I, et al. (2011) Vitamin D, parathyroid hormone, and cardiovascular events among older adults. J Am Coll Cardiol 58, 1433-1441.

30. Brøndum-Jacobsen P, Benn M, Jensen GB, et al. (2012) 25-hydroxyvitamin D levels and risk of ischemic heart disease, myocardial infarction, and early death: population-based study and meta-analyses of 18 and 17 studies. Arterioscler Thromb Vasc Biol 32, 2794-2802.

31. Skaaby T, Husemoen LL, Pisinger C, et al. (2012) Vitamin D status and cause-specific mortality: a general population study. PLOS ONE 7, e52423.

32. Cawthon PM, Parimi N, Barrett-Connor E, et al. (2010) Serum 25-hydroxyvitamin D, parathyroid hormone, and mortality in older men. J Clin Endocrinol Metab 95, 4625-4634.

33. Gerling ME, James MT, Wilton SB, et al. (2016) Serum total $25-\mathrm{OH}$ vitamin $\mathrm{D}$ adds little prognostic value in patients undergoing coronary catheterization. J Am Heart Assoc 5, e004289.

34. Zhen D, Liu L, Guan C, et al. (2015) High prevalence of vitamin $\mathrm{D}$ deficiency among middle-aged and elderly individuals in northwestern China: its relationship to osteoporosis and lifestyle factors. Bone 71, 1-6.

35. Ameri P, Ronco D, Casu M, et al. (2010) High prevalence of vitamin $\mathrm{D}$ deficiency and its association with left ventricular dilation: an echocardiography study in elderly patients with chronic heart failure. Nutr Metab Cardiovasc Dis 20, 633-640.

36. Cesari M, Penninx BW, Newman AB, et al. (2003) Inflammatory markers and onset of cardiovascular events: results from the Health ABC study. Circulation 108, 2317-2322.

37. Boxer RS, Dauser DA, Walsh SJ, et al. (2008) The association between vitamin $\mathrm{D}$ and inflammation with the 6-minute walk and frailty in patients with heart failure. J Am Geriatr Soc 56, 454-461.

38. Selles J, Bellido T \& Boland R (1994) Modulation of calcium uptake in cultured cardiac muscle cells by 1,25-dihydroxyvitamin $\mathrm{D}_{3}$. J Mol Cell Cardiol 26, 1593-1599.

39. Beuckelmann DJ, Nabauer M \& Erdmann E (1992) Intracellular calcium handling in isolated ventricular myocytes from patients with terminal heart failure. Circulation $\mathbf{8 5}$, 1046-1055.

40. Xiang W, Kong J, Chen S, et al. (2005) Cardiac hypertrophy in vitamin D receptor knockout mice: role of the systemic and cardiac renin-angiotensin systems. Am J Physiol Endocrinol Metab 288, E125-E132.

41. Takeda M, Yamashita T, Sasaki N, et al. (2010) Oral administration of an active form of vitamin $\mathrm{D}_{3}$ (calcitriol) decreases atherosclerosis in mice by inducing regulatory $\mathrm{T}$ cells and immature dendritic cells with tolerogenic functions. Arterioscler Thromb Vasc Biol 30, 2495-2503.

42. Tarcin O, Yavuz DG, Ozben B, et al. (2009) Effect of vitamin D deficiency and replacement on endothelial function in asymptomatic subjects. J Clin Endocrinol Metab 94, 4023-4030.

43. Shedeed SA (2012) Vitamin D supplementation in infants with chronic congestive heart failure. Pediatr Cardiol 33, 713-719.

44. Boxer RS, Hoit BD, Schmotzer BJ, et al. (2014) The effect of vitamin $d$ on aldosterone and health status in patients with heart failure. J Card Fail 20, 334-342.

45. Moretti HD, Colucci VJ \& Berry BD (2017) Vitamin D 3 repletion versus placebo as adjunctive treatment of heart failure patient quality of life and hormonal indices: a randomized, double-blind, placebo-controlled trial. BMC Cardiovasc Disord 17, 274.

46. D'Amore C, Marsico F, Parente A, et al. (2017) Vitamin D deficiency and clinical outcome in patients with chronic heart failure: a review. Nutr Metab Cardiovasc Dis 27, 837-849.

47. Jiang WL, Gu HB, Zhang YF, et al. (2016) Vitamin D supplementation in the treatment of chronic heart failure: a meta-analysis of randomized controlled trials. Clin Cardiol 39, 56-61.

48. Witham MD, Crighton LJ, Gillespie ND, et al. (2010) The effects of vitamin D supplementation on physical function and quality of life in older patients with heart failure: a randomized controlled trial. Circ Heart Fail 3, 195-201.

49. Cozzolino M, Ketteler M \& Zehnder D (2010) The vitamin D system: a crosstalk between the heart and kidney. Eur J Heart Fail 12, 1031-1041. 